\title{
Histological and Physiological Studies of the Effect of Bone Marrow-Derived Mesenchymal Stem Cells on Bleomycin Induced Lung Fibrosis in Adult Albino Rats
}

\author{
Dina Mohamed Zakaria ${ }^{1}$ Noha Mahmoud Zahran ${ }^{1} \cdot$ Samia Abdel Aziz Arafa ${ }^{1} \cdot$ \\ Radwa Ali Mehanna ${ }^{2,3}$ - Rehab Ahmed Abdel-Moneim ${ }^{1}$
}

Received: 9 July 2020/Revised: 4 August 2020/Accepted: 15 August 2020/Published online: 22 October 2020

(C) The Korean Tissue Engineering and Regenerative Medicine Society 2020

\begin{abstract}
BACKGROUND: Lung fibrosis is considered as an end stage for many lung diseases including lung inflammatory disease, autoimmune diseases and malignancy. There are limited therapeutic options with bad prognostic outcome. The aim of this study was to explore the effect of mesenchymal stem cells (MSCs) derived from bone marrow on Bleomycin (BLM) induced lung fibrosis in albino rats.

METHODS: 30 adult female albino rats were distributed randomly into 4 groups; negative control group, Bleomycin induced lung fibrosis group, lung fibrosis treated with bone marrow-MSCs (BM-MSCs) and lung fibrosis treated with cell free media. Lung fibrosis was induced with a single dose of intratracheal instillation of BLM. BM-MSCs or cell free media were injected intravenously 28 days after induction and rats were sacrificed after another 28 days for assessment. Minute respiratory volume (MRV), forced vital capacity (FVC) and forced expiratory volume 1 (FEV1) were recorded using spirometer (Power lab data acquisition system). Histological assessment was performed by light microscopic examination of H\&E, and Masson's trichrome stained sections and was further supported by morphometric studies. In addition, electron microscopic examination to assess ultra-structural changes was done. Confocal Laser microscopy and PCR were used as tools to ensure MSCs homing in the lung.

RESULTS: Induction of lung fibrosis was confirmed by histological examination, which revealed disorganized lung architecture, thickened inter-alveolar septa due excessive collagen deposition together with inflammatory cellular infiltration. Moreover, pneumocytes depicted variable degenerative changes. Reduction in MRV, FVC and FEV1 were recorded. BM-MSCs treatment showed marked structural improvement with minimal cellular infiltration and collagen deposition and hence restored lung architecture, together with lung functions.

CONCLUSION: MSCs are promising potential therapy for lung fibrosis that could restore the normal structure and function of BLM induced lung fibrosis.
\end{abstract}

Keywords Lung fibrosis - Bleomycin - Mesenchymal stem cell

Electronic supplementary material The online version of this article (https://doi.org/10.1007/s13770-020-00294-0) contains supplementary material, which is available to authorized users.

Radwa Ali Mehanna

radwa.mehanna@alexmed.edu.eg

1 Department of Histology and Cell Biology, Faculty of Medicine, Alexandria University, Alexandria, Egypt

2 Department of Physiology, Faculty of Medicine, Alexandria University, Alexandria, Egypt
Center of Excellence for Research in Regenerative Medicine and Applications (CERRMA), Faculty of Medicine, Alexandria University, Azareeta, Khartoom Square, Alexandria 21526, Egypt 


\section{Introduction}

Lung fibrosis is a progressive fatal disease that affects many patients worldwide. It is the end-stage of many lung diseases. The main histopathological characteristic features of lung fibrosis are excessive deposition of extracellular matrix, accretion of fibroblasts, collapsing of alveoli and loss of normal lung architecture [1-3].

Causes of lung fibrosis include lung inflammatory disease, autoimmune diseases, hypersensitivity pneumonitis, drug-induced interstitial lung disease, infection, and malignancy. However, idiopathic lung fibrosis (IPF) is considered to be one of the most common and aggressive forms of lung fibrosis with high mortality and morbidity. It develops without an identified underlying cause and terminates with severe affection of lung functions. There are many risk factors for the development of IPF, the most important of which is cigarette smoking, where the history of cigarette smoking has been associated with sporadic and familial cases. Moreover, IPF was suggested to be linked to chronic exposure to air pollutants and recurrent pulmonary infection, whether bacterial or viral $[4,5]$.

Adding to the burden is the global spread of the COVID19 pandemic caused by SARS- COV2 virus and the shown evidence of scarring on some patients' lungs during or after recovering from the illness. Yet still, there is no evidence whether this scarring is progressive or not [6]. Unfortunately, once lung scarring occurs, it cannot be reversed, so there is no cure for lung fibrosis, whatever the cause.

Only limited therapeutic options are available, making lung fibrosis a life-threatening disease. Surgical therapy is the last option where lung transplantation has been the only effective treatment proved $[7,8]$.

Recently, regenerative medicine has become a remarkably valuable therapeutic strategy in different diseases, where it presents a promising modality that can replace organ transplantation with all its hazards. Owing to their unique properties, stem cells turned out to be the main pillar in regenerative medicine due to its controlled yet unlimited self-renewal capacity, and its differentiation ability into different specific cell lines. Adult mesenchymal stem cells (MSCs) isolated from the bone marrow, umbilical cord, and adipose tissue are the most commonly used [9].

MSCs have potent regenerative, angiogenic, anti-apoptotic, immune-modulatory, and anti-inflammatory properties, besides their multilineage capacity, which make them able to differentiate into a wide range of cell lines and thus have a great therapeutic potential for different diseases. This is besides their accessibility, homing, and engraftment at the site of injury and their ability to modify the microenvironmental factors at the engraftment site by the molecules and vesicles they secret known as extracellular vesicles $[10,11]$.

Bleomycin (BLM) is a chemotherapeutic agent that is used widely in the treatment of many malignancies as classical Hodgkin lymphoma, melanoma, ovarian carcinoma, and testicular neoplasms [12-14]. However, it has serious side effects on the lung. The use of BLM is limited by the development of pulmonary fibrosis in $3-5 \%$ of patients receiving this chemotherapeutic agent [15].

It is distributed mainly in the liver and spleen but also lungs. The kidney and heart receive a considerable amount of BLM as well. However, BLM selectively affects the lung because it lacks the enzyme bleomycin hydrolase that hydrolyzes the L-aminoalanine moiety of BLM. This step prevents the metabolite of BLM from binding metals such as iron, thus triggering an oxidative stress reaction [16]. As such, it has been the agent of choice for the induction of lung fibrosis model.

In such context, the current study, assessed the effect of stem cell therapy using MSCs for treatment of BLM induced lung fibrosis model.

\section{Materials and methods}

\subsection{Animals and study design}

The study was conducted on 35 Sprague-Dawley albino rats. Five male rats aged 3 weeks (27-32 g) were used for bone marrow isolation and thirty female rats weighing 150-200 g 6-8 weeks of age were used in the experimental groups. Rats were allowed to acclimate for 2 weeks before the experiment and were housed under a $14-10 \mathrm{~h}$ lightdark cycle with food and water provided ad libitum. Experiments were conducted in accordance with the approved guidelines set by the Research Ethics Committee of Alexandria Faculty of Medicine, Egypt.

Stem cell processing was carried out in the Center of Excellence for Research in Regenerative Medicine and its Application (CERRMA), Alexandria Faculty of Medicine. Ethical approval was attained from the Medical Ethics Committee of Alexandria Faculty of Medicine (IRB NO: 00012098-FWA NO: 00018699).

The 30 female rats were divided randomly into 2 groups;

Control Group, $\mathrm{n}=10$, which was further subdivided into a negative control group (CG) and a positive control group, in the latter lung fibrosis was induced for optimization of model and named fibrotic group (FG). These groups were given an intratracheal injection of saline or a single dose of bleomycin $(5 \mathrm{mg} / \mathrm{kg}$ body weight, in $0.4 \mathrm{ml}$ of saline) respectively. Vial of bleomycin powder was dissolved in $5 \mathrm{ml}$ saline. Animals were held in 'upright 
position by an assistant and the neck was pulled backward. A syringe filled with BLM was fitted to an orogastric tube, and then was pushed gently against the soft palate to reach the trachea. Induction of lung fibrosis was assessed 28 days after bleomycin injection [17].

Experimental Group (where lung fibrosis was induced) EG $\mathrm{n}=20$, then it was subdivided into; Bone marrow-derived mesenchymal stem cells treated group (BM-MSCsG) where rats were injected with a single dose of passage 3 (P3) BM-MSCs in complete media, and cell free media treated group $(\mathrm{CFG})$ where rats were injected once with cell free complete media, intravenously 28 days after induction of fibrosis. Histological assessment was done after another 28 days from treatment and was further supported by physiological assessment of lung functions.

The bleomycin used in the current study was commercially purchased as Bleocel 15 IU Injection: bleomycin sulfate powder for solution for injection/infusion manufactured by celon Labs.

\subsection{Isolation and culturing of BM-MSCs}

Five male rats were sacrificed by overdose anesthesia (100 $\mathrm{mg} \backslash \mathrm{Kg}$ phenobarbital) under a class II biosafety cabinet, for the collection of bone marrow. The femur and tibia were dissected bilaterally and all excess tissue was removed. Dissected intact bones were soaked in $70 \%$ ethanol in a sterile petri dish for $2 \mathrm{~min}$ for disinfection, then washed with phosphate buffer saline PBS (PBS, Lonza, Bornem, Belgium) and finally placed in culture medium in a sterile petri dish for flushing the bone marrow. The proximal and the distal ends of both tibiae and femurs were trimmed and the bone marrow was flushed by inserting a 23-gauge needle attached to a $5 \mathrm{ml}$ syringe with complete culture medium (CCM) [18-20].

Bone marrow cells were cultured in complete media (low glucose Dulbecco's Modified Eagle Medium (LGDMEM) (1.0 g/L glucose, Sigma-Aldirch, St. Louis, MO, USA) supplemented with $10 \%$ Fetal bovine serum (FBS, Sigma-Aldirch), $1 \%$ L-glutamine (Lonza) and 1\%Penicillin/streptomycin (pen/strept, Lonza) and incubated in a $\mathrm{CO} 2$ incubator at $37{ }^{\circ} \mathrm{C}$ in a humidified atmosphere with $5 \% \mathrm{CO} 2$.

After $48 \mathrm{~h}$ the medium was discarded, and the cells were washed with PBS and fed with a fresh complete medium. During the proliferation period, the medium was replaced twice weekly. Cells were split after reaching 70-80\% confluence using $0.025 \%(\mathrm{w} / \mathrm{v})$ trypsin/EDTA (Thermo Fisher Scientific, Waltham, MA, USA) in a ratio 1:3 [21-23].

MSCs at passage three P3 were used in the current experiment. Follow-up of cultured cells was done using inverted phase contrast microscope equipped with the digital camera. (Olympus CKX41SF, Tokyo, Japan) [22].

\subsection{Characterization of mesenchymal stem cells}

\subsubsection{Colony forming unit-fibroblast (CFU-F) assays}

The colony-forming potential of the cultured cells at passage 3 was tested. In this assay, 100 cells were plated on a six-well plate in complete media and incubated for 14 days. The cells were fixed and stained for $30 \mathrm{~min}$ at room temperature in $3.0 \%$ crystal violet solution (Sigma Aldrich) in $100 \%$ methanol. The number of colonies for each well was counted and the plating efficiency or-CFU potential was calculated as the number of colonies formed/ number of cells plated $\times 100$. All visible colonies were counted; the number of colonies displaying five or more cells was scored under the phase-contrast inverted microscope. A CFU potential of over $40 \%$ was considered to be optimal for MSCs' culture [24].

\subsubsection{Immunophenotyping characterization using the flow cytometer}

Cells were characterized using fluorescent-labeled monoclonal antibodies (mAb) for CD90 and CD 45 markers. Trypsinized cells at passages 3 were incubated at room temperature for $30 \mathrm{~min}$ in the dark, with monoclonal phycoerythrin (PE)-conjugated antibody for CD45 (Abcam, ab23396, Cambridge, UK) and monoclonal Allophycocyanin-conjugated antibody for CD90 (Anti-Thy1.1) (Abcam, ab225). Immunofluorescence on cells was analyzed using Becton-Dickinson, FACS caliber flow cytometer equipped with Cell Quest software [25].

\subsection{Injection of BM-MSCs (In vivo animal study)}

A count of $2 \times 10^{6}$ BM-MSCs in $1 \mathrm{ml}$ complete media or $1 \mathrm{ml}$ of complete media without cells were injected intravenously in the tail vein of BM-MSCs treated and cell free media treated groups respectively [26-28].

\subsection{Homing of BM-MSCs into injured lung tissue}

\subsubsection{Cell labeling}

Before injection of BM-MSCs, the cells' cytoplasmic membranes were labeled with fluorescent probe (chloromethyl - benzamide octadecyl indocarbocyanines (CMDiI)) (molecular probes, Thermo Fisher Scientific). Labeled cells were viewed under confocal laser microscopy (Leica microsystems, DMi8, Wetzlar, Germany) $72 \mathrm{~h}$ after injection in the lung tissue of 2 rats [29]. 


\subsubsection{Real time-quantitative polymerase chain reaction} (RQ-PCR) for detection of the Y chromosome

The lung tissues were processed for identification of male BM- MSCs which were injected into female rats through identification of $\mathrm{Y}$ chromosome; using real-time quantitative polymerase chain reaction [30, 31]. Detection of SRY DNA was performed using the following primers; forward (5-CATCGAAGGGTTAAAGTGCCA-3) and reverse (5ATAGTGTGTAG- GTTGTTGTCC-3) [32, 33]. Real-time PCR amplification, data acquisition, and analysis were carried out using the Real-Time detection system Software (Applied Biosystems 7500, Foster City, CA, USA).

\subsection{Assessment of lung fibrosis and the effect of BM- MSCs on lung regeneration}

\subsubsection{Lung function assessment}

Pulmonary function tests [tidal volume (VT), minute respiratory volume (MRV), forced vital capacity (FVC), forced expiratory volume (FEV1) and FEV1/FVC ratio] were assessed using a Power Lab digital data acquisition system (4/25, AD Instrument, Bella Vista, Australia), 28 days after BM-MSCs or cell free media injection and before sacrifice of rats. The ventilatory parameters were recorded using a pneumotachometer MLT1L (Lab chart 8, AD Instruments, Castle Hill, NSW, Australia) with P1 channel end connected to the outlet of the NP/Whole Body Plethysmography (WBP).

\subsubsection{Histological and histochemical assessment}

At the end of the study, 28 days after treatment, all rats were sacrificed and both lungs were dissected, then each lung was divided into two pieces.

One piece was fixed in $10 \%$ neutral-buffered formalin, then processed to obtain $(6 \mathrm{um})$ thin sections. Some sections were routinely stained with $\mathrm{H} \& \mathrm{E}$ and others with Masson's trichrome for light microscopic examination using, (Olympus BX41) equipped with spot digital camera (Olympus DP20). Histomorphometric study was done, using NIH Fiji $\odot$ program (NIH, Bethesda, MD, USA), where the area percentage of collagen fibers in Masson' trichrome stained sections inter-alveolar septal thickness and alveolar surface area in $\mathrm{H} \& \mathrm{E}$ stained sections, were measured in five randomly selected sections for each item. Data was presented as mean \pm standard deviation (SD) of randomly selected ten fields/section ( $n=5 /$ group)[34].

The second piece was cut into small pieces $(1 / 2-1 \mathrm{~mm} 3)$ and immediately fixed in 3\% phosphate buffered glutaraldehyde $\mathrm{pH} \mathrm{7.4,} \mathrm{then} \mathrm{processed} \mathrm{to} \mathrm{obtain} \mathrm{ultra-thin}$ sections for transmission electron microscope examination,
TEM (JEM-100 CX Electron Microscope, JEOL, Tokyo, Japan) [35-37].

\subsection{Statistical analysis}

Data were analyzed using IBM SPSS software package version 20.0. (Armonk, NY, USA: IBM Corp). Qualitative data were described as number and percent. Quantitative data were described as the mean \pm standard deviation. The studied groups were compared using a 2-sided -test and one way ANOVA with post hoc test (Tukey's) for pairwise comparison. The $p$ value was judged at the 5\% level [38].

\section{Results}

\subsection{Characterization of BM-MSCs}

\subsubsection{Morphological characterization}

The cell cultures were monitored daily using contrast phase inverted light microscope. In primary culture $\mathrm{P} 0$, cells were small and rounded, they started to be spindle in shape after $48 \mathrm{~h}$ of culture, displaying a heterogeneous population and reached $70-80 \%$ confluency in approximately 7-9 day. With passaging, cell growth tended to be accelerated and morphology changed gradually exhibiting large, flattened and spindle shaped cells. Mitotic rounded cells appeared demonstrating proliferation. At $\mathrm{p} 3$ the culture represented a homogenously fibroblastic like cell monolayer (Fig. 1AC).

\subsubsection{Colony forming unit-fibroblast (CFU-F) assays}

After 5-7 days of incubation, cells gradually proliferated into small colonies, which increased after 2 weeks of culture to form larger colonies. Two weeks post seeding, colonies were made obvious with crystal violet staining (Fig. 1D). The colony-forming assay showed that each well with 100 cells gave $90 \% \pm 1.06$ of colonies after 14 days.

\subsubsection{Immunophenotyping of MSCs by flow cytometry}

FACS analysis for BM-MSCs passage 3 showed that 98.04\% of the cultured cells expressed the mesenchymal multipotent CD90 surface marker, while they were negative for the CD45 hematopoietic marker (Fig. 1E).

\subsection{Homing of BM-MSCS into lung tissue}

Labeled BM-MSCs were tracked in lung tissue $72 \mathrm{~h}$ after injection. BM-MSCs were seen in the alveolar pneumocytes type 1 under the laser scanning confocal microscope 

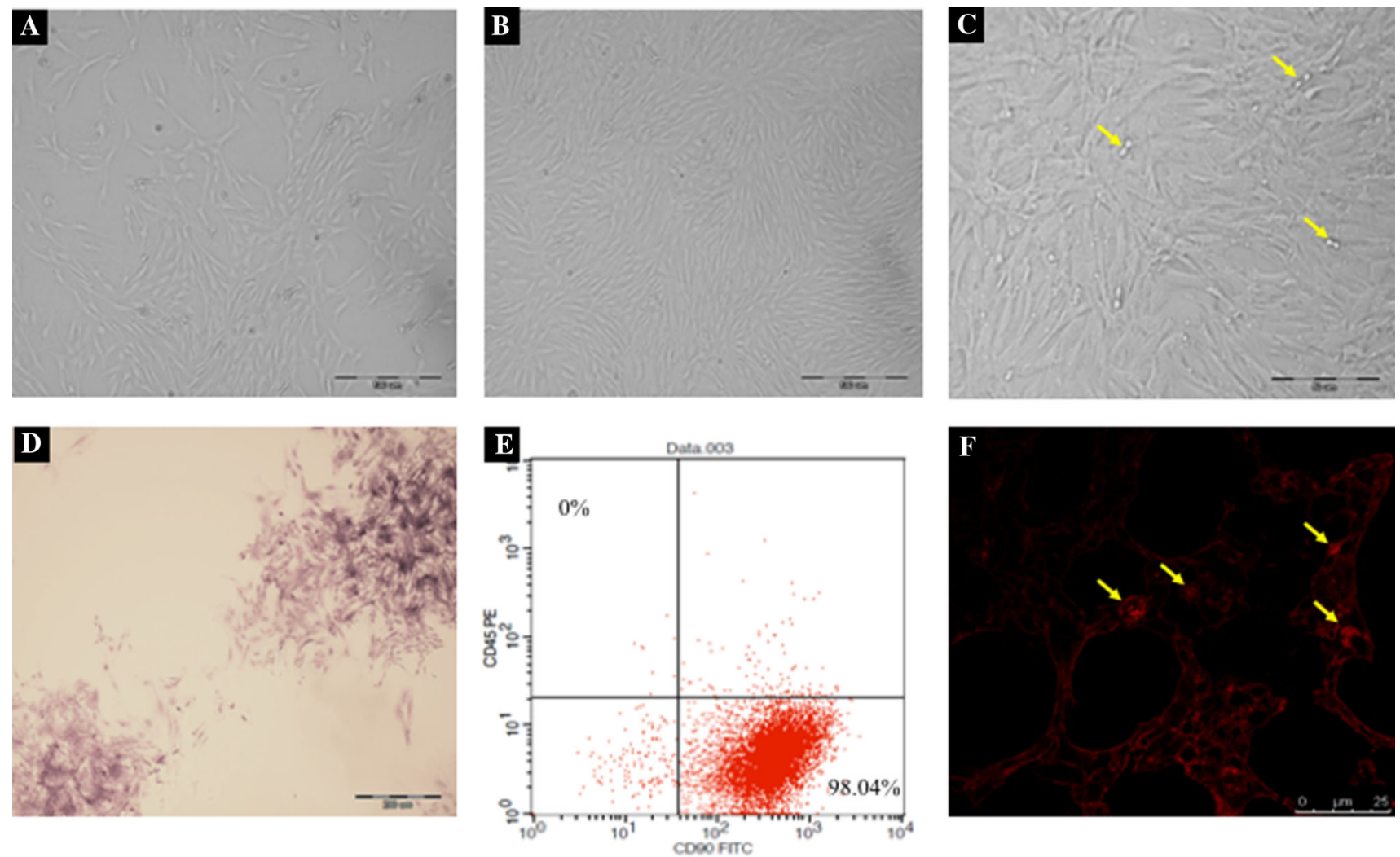

Fig. 1 A-C Phase contrast inverted microscope, Morphological characteristics of BM-MSCs showing (A) passage 3,50\% confluent spindle fibroblast like cells, ( $\times 100$ ) (B) passage $380 \%$ confluent spindle fibroblast like cells forming monolayer $(\times 100)$. (C) High magnification of passage 3,90\% confluent spindle fibroblast like cells, some small rounded cells undergoing mitotic division, proliferating cells. (Yellow arrow) $(\times 200)$. D CFU assay, P3 Crystal Violet

(Fig. 1F). RQ-PCR results showed that SRY gene was expressed in female rats injected by male BM-MSCs. The expression of SRY gene in BM-MSCsG was 3.10 folds in comparison to CG (Supplementary Table S1).

\subsection{Lung function assessment}

FG had shown a significant decrease in MRV, FVC and FEV1 by $72 \%, 26 \%$ and $25 \%$ respectively as compared to control group $p \leq 0.05$. Also, a significant decrease was seen in CFG 71\%, 25\% and 24\% regarding MRV, FVC and FEV1 respectively in comparison to FG. Treatment with BM- MSCs caused a significant increase in measured parameters compared to $\mathrm{CG}$ and $\mathrm{CFG}$ reaching control values, where MRV increased by $75 \%$, FVC and FEV1 increased by $25 \%$ compared to FG and CFG $p \leq 0.05$.

FEV1-FVC (\%) showed normal ratio with no significant difference between all groups (Supplementary Table S2, Fig. 2A,B). stain showing 2 colonies. E Flow cytometric analysis of cell-surface markers of BM-MSCs at passage 3,98.04\% of the cultured cells expressed the mesenchymal cell marker CD90 in lower right quadrant and cells were negative for the CD45 hematopoietic marker, upper left quadrant. F Red florescent Dil labeled BM-MSCs visualized under Confocal Laser Microscope in the lung tissues (yellow arrows pointing to BM-MSCs), $\times 63$, scale bars $25 \mu \mathrm{m}$

\subsection{Histological assessment}

\subsubsection{Haematoxylin and eosin stain}

Normal architecture of lung tissue was observed by using light microscope in lung sections of $\mathrm{CG}$, where thin interalveolar septa and patent alveoli were noticed. Pneumocytes type I with typical flattened nuclei and type II with rounded nuclei bulging into alveolar lumen, were observed lining the alveoli. Bronchioles appeared patent and lined with simple columnar epithelium (Fig. 3A, B). In FG, extensive degenerative changes and distortion of lung architecture were observed in a patchy pattern, where most of alveoli appeared collapsed. In addition, markedly thickened inter-alveolar septa with extensive cellular infiltration were observed in most areas of the lung tissue. Blood vessels revealed evident congestion. As regards the bronchioles, massive lymphocytic infiltration around bronchiolar wall was noticed, together with evident 
A

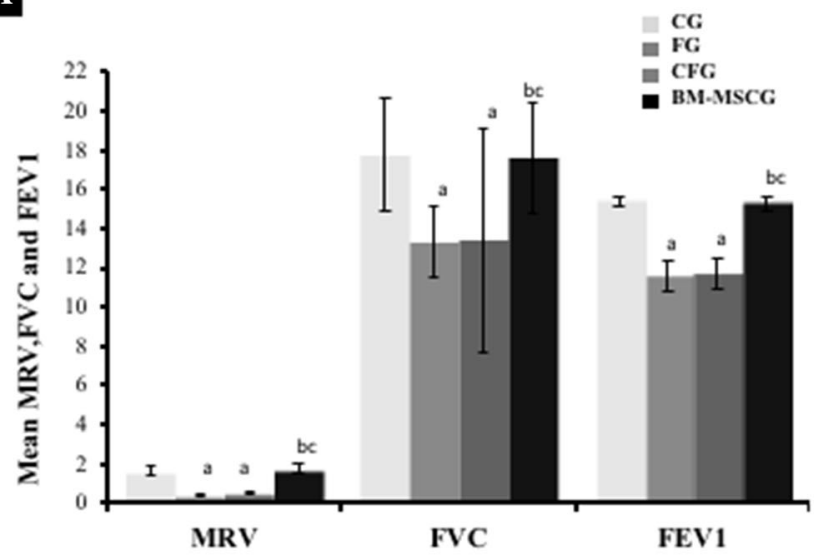

B

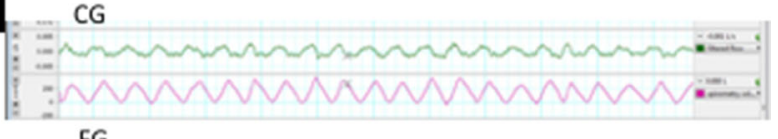

FG

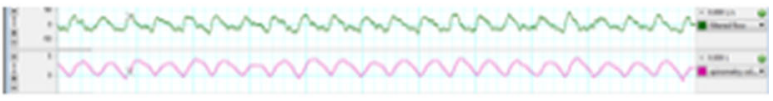

CFM

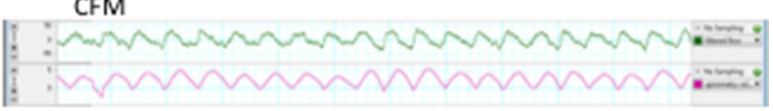

BM-MSCG

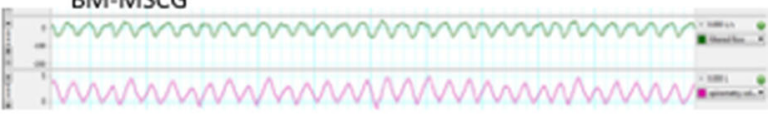

C

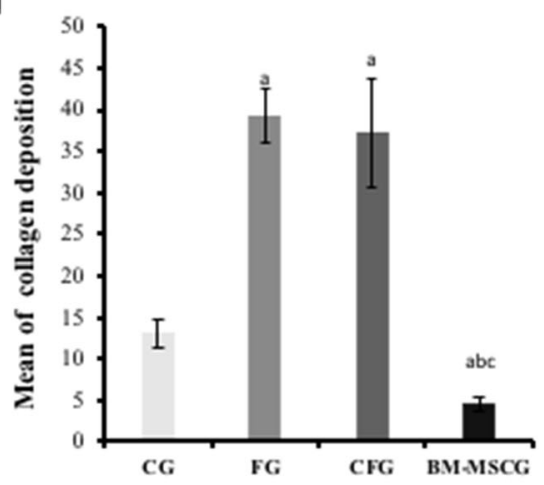

D

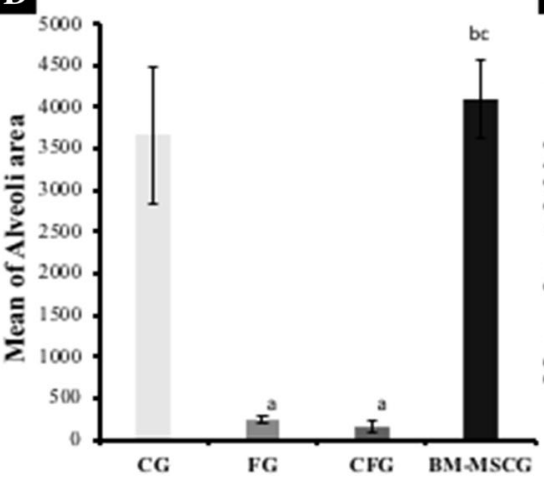

$\mathbf{E}$

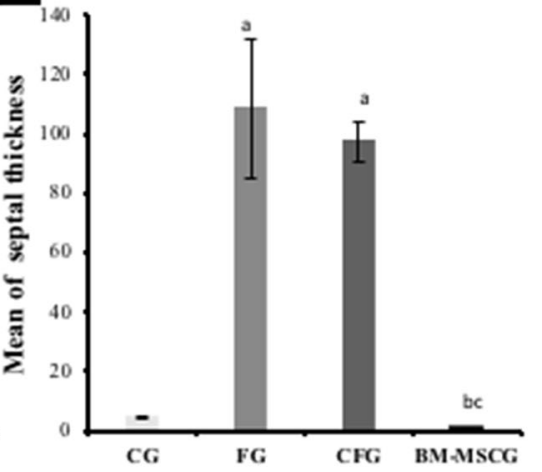

Fig. 2 Quantitative assessment of Pulmonary functions and morphometric analysis. A Mean values of MRV, FVC and FEV1 B Representative tracings of airway flow (upper) and tidal volume (lower) in each panel of the different studied groups Showing decreased airway flow and tidal volume in CG and CFG $\mathbf{C}$ Mean of collagen deposition D Mean of Alveolar area E Mean of alveolar thickness. a; significant compared to control. b: significant compared to FG c; significant

bronchiolar epithelial desquamation, which was seen in lumen (Fig. 3C, D).

Marked amelioration of degenerative signs with evident restoration of lung architecture was seen in BM-MSCs treated group when compared to FG, where most of the alveoli appeared patent with thin inter-alveolar septa. Focal areas of limited thickening of inter-alveolar septa were still noticed. Almost normal appearance of bronchioles was also observed. However, limited remnant blood vessel congestion was still seen (Fig. 4A, B). Examination of lung sections in rats that received cell free media $\mathrm{CFG}$, revealed excessive thickening of the inter-alveolar septa associated with evident cellular infiltration. Most of the alveoli appeared with collapsed lumina, while some other alveoli appeared with narrowing of their lumina. Diffuse extravasation of RBCS was also noticed (Fig. 4C, D). compared to CFG. Pairwise comparison bet. each 2 groups using Post Hoc Test Tukey) Significance at $p \leq 0.05$. Error bars represent S.E.M. $\mathrm{n}=5$ for all groups (a), $\mathrm{n}=6$ for all groups in (b,c,d). Abbreviations: CG; control group, FG; fibrosis group, CFG; cell free media treated group, BM-MSCG; mesenchymal stem cells treated group, MRV; minute respiratory volume, FVC; forced vital capacity,FEV1; forced expiratory volume 1

\subsubsection{Masson's trichrome stain}

Marked increase in trichrome green stained areas, indicating massive collagen deposition was noticed, within inter-alveolar septa, around blood vessels and bronchioles in FG in comparison to CG. In CG normal pattern of trichrome stained areas, thus reflecting normal collagen distribution within the inter-alveolar septa was demonstrated (Fig. 5A, B).

Examination of the lung sections of BM-MSCSsG revealed limited and focal distribution of green colored trichrome stained areas within the inter-alveolar septa as compared to CFG, which appeared to be more diffuse and extensive within the inter-alveolar septa, hence reflecting remarkable decrease in collagen deposition in BMMSCSsG (Fig. 5C, D). The Morphometric analysis of 


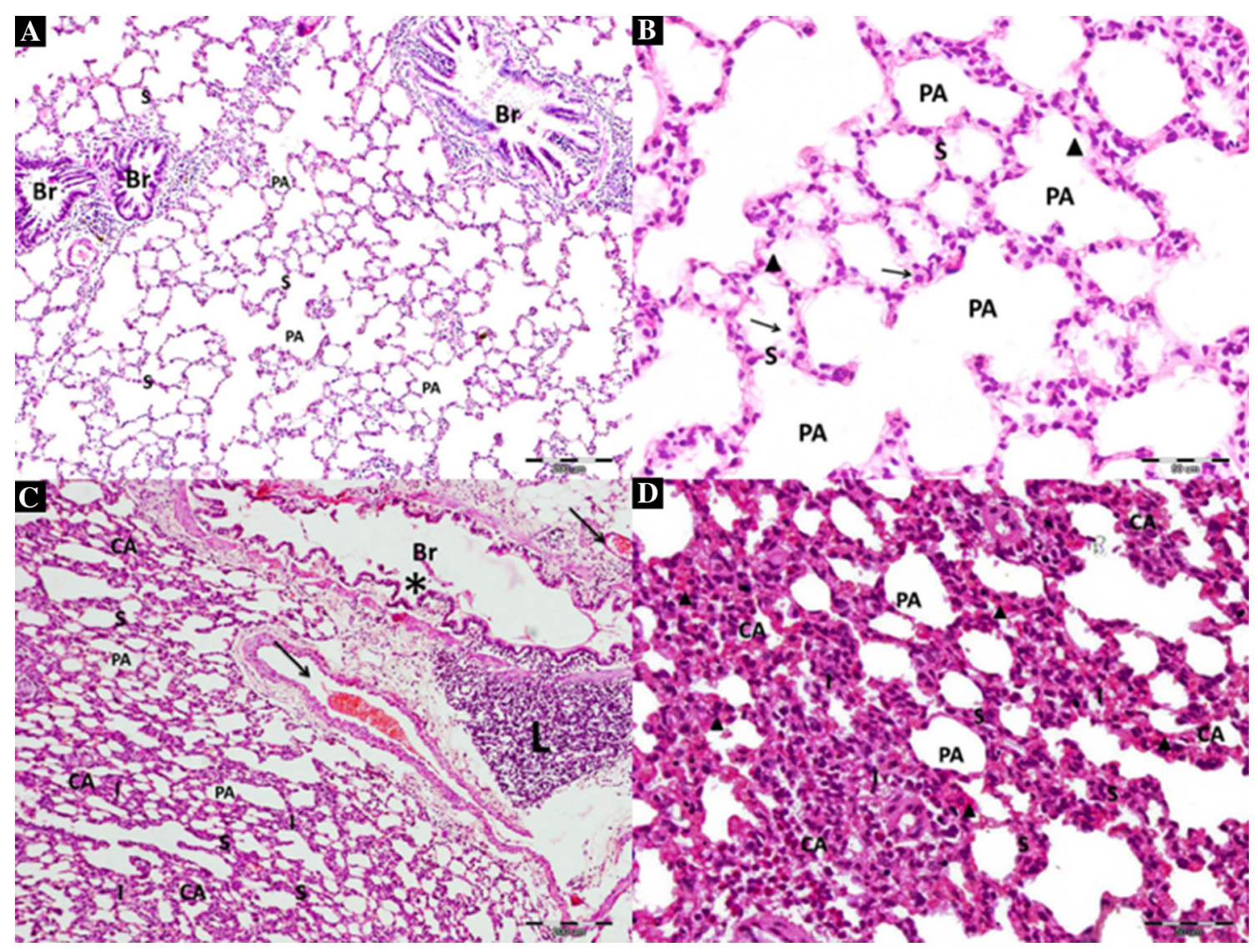

Fig. 3 H\& E stained lung sections. A and B Photomicrographs of CG. A Patent alveoli (PA) with thin classical inter-alveolar septa (S) are observed. Bronchioles $(\mathrm{Br})$ appear lined by folded simple columnar epithelium, scale bar $200 \mu \mathrm{m}$. B Type I pneumocytes (arrowheads) are observed with their typical flat nuclei. Type II pneumocytes (arrows) appear cuboidal with rounded nuclei, scale bar $50 \mu \mathrm{m}$. C and D Photomicrographs of FG. Most of the alveoli appear collapsed (CA). Evident thickening of inter-alveolar septa (S) with massive cellular infiltration (I) are observed. Marked congestion of blood vessels (arrows) is noticed. Bronchiolar (Br) epithelium desquamation (asterisk) is noticed into the lumen. Marked peribronchiolar lymphocytic infiltration (L) is also observed. Limited areas appear with patent alveoli (PA). (D) Diffuse extravasation of RBCS is also noticed (arrowheads), scale bar C $200 \mu \mathrm{m}$, D 50 $\mu \mathrm{m}$. (H\&E stain, $\mathrm{A} \times 100, \mathrm{~B} \times 400, \mathrm{C} \times 100, \mathrm{D} \times 400)$

CG with mean of $236.8 \pm 35.12$ vs. $3659.1 \pm 832.5$ respectively $(p<0.001)$. On the other hand, BM-MSCsG showed a significant increase in the surface area of alveoli $4095.2 \pm 454.8$ in comparison to FG and CFG. The alveolar surface area of BM-MSCsG reached that of the CG with no significant difference between them $(p<0.001)$. (Supplementary Table S3, Fig. 2D).

The inter-alveolar septal thickness was also measured to evaluate the degree of interruption of air-blood barrier that occurred as a consequence of collagen deposition. BMMSCsG showed significant decrease of inter-alveolar septal thickness in comparison to group FG and CFG showing thickness of $0.88 \pm 0.31,108.5 \pm 23.3$ and $97.31 \pm 6.80$ respectively. Yet, there was not a significant difference between BM-MSCsG and CG $4.60 \pm 0.37$. (Supplementary Table S3, Fig. 2E). 


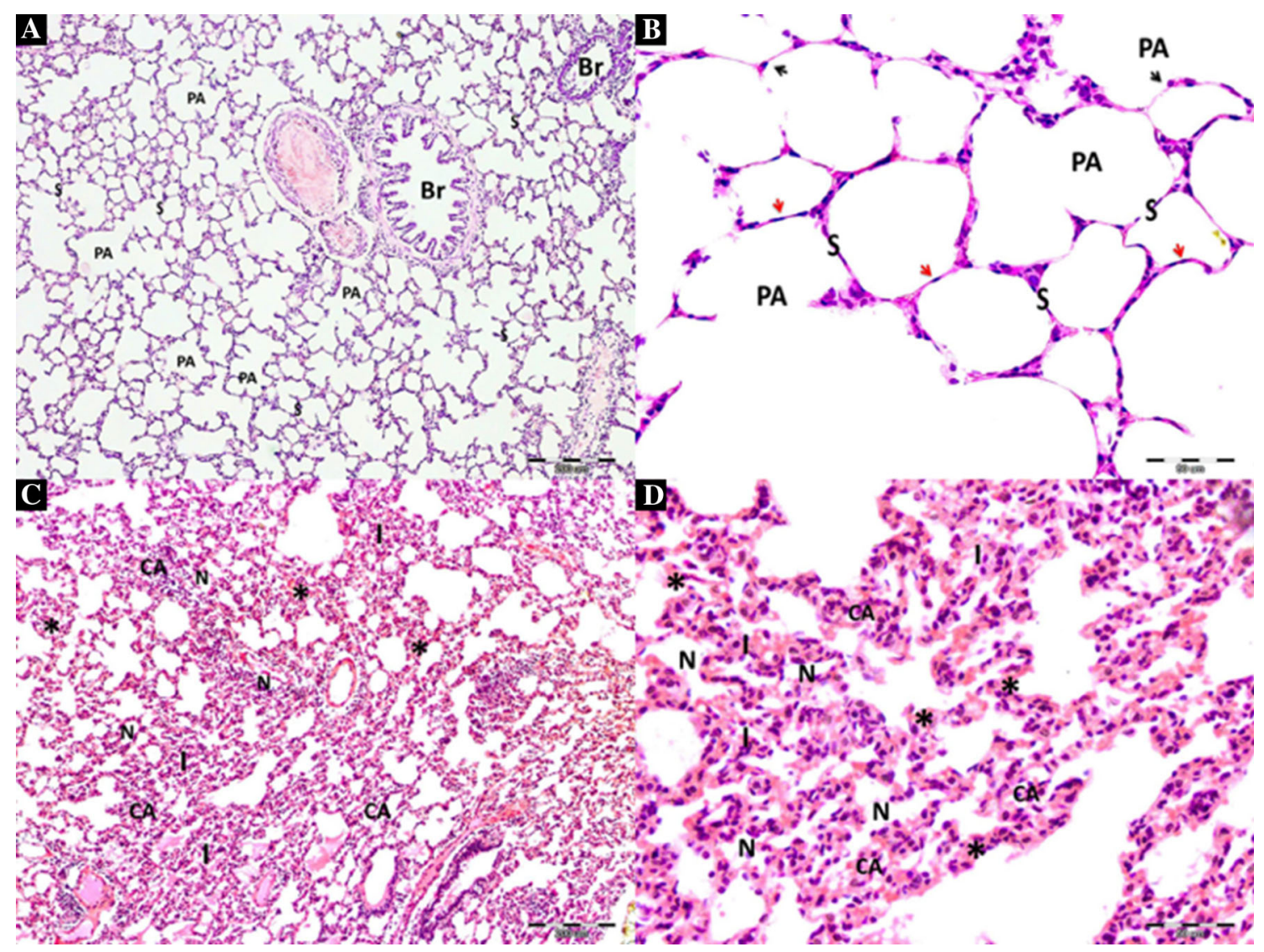

Fig. 4 H\& E stained lung sections. A and B Photomicrographs of BM-MSCsG (A) Alveoli appear patent (PA) with thin inter-alveolar septa $(\mathrm{S})$. A bronchiole $(\mathrm{Br})$ is observed lined by folded simple columnar epithelium. (B) Most of alveolar surface area is seen lined by type I cells (red arrows). Type II cells (black arrows) appear cuboidal with rounded nuclei. $\mathbf{C}$ and $\mathbf{D}$ Photomicrographs of CFG,

\subsubsection{Electron microscopic results}

CG depicted patent alveoli, where pneumocyte type II was observed with its characteristic, apical microvillus boarder and abundant lamellar bodies within the cytoplasm. Pneumocyte type I was observed with its basal lamina fused with those endothelial cells of the neighboring blood capillary. Endothelial lining of blood capillaries showed normal regular outline with normal euchromatic nucleus (Fig. 6A, B). On the other hand, variable degenerative changes were encountered ultra-structurally in FG, where, some type II pneumocytes exhibited vacuolated lamellar bodies with loss of lamellar arrangement. Luminar surface of some other type II cells depicted decreased and irregular microvilli. In addition, nuclear changes were noticed in some pneumocytes that showed irregular nuclear membrane together with increased condensed chromatin (Fig. 6C, D). Apoptotic bodies from type II cells were also observed in some areas (Fig. 6D). Inter-alveolar septa revealed prominent Fibroblasts together with evident revealing most of the alveoli with collapsed lumina (CA), while some other alveoli appear with limited narrowing of their lumina $(\mathrm{N})$. Marked inter-alveolar septa thickening with cellular infiltration is seen (I). Diffuse extravasation of RBCS is also noticed (asterisks). (H\&E stain, $\mathrm{A} \times 100, \mathrm{~B} \times 400, \mathrm{C} \times 100, \mathrm{D} \times 400)$

collagen deposition. The alveolar lumen showed marked narrowing and even obliteration in some areas. As regards Type I pneumocytes, they were less frequently encountered than type II pneumocyte. Alveolar macrophages and extravasated RBCs were also seen in the inter-alveolar septum. Examination of endothelial lining of inter-alveolar capillaries revealed irregular outline of the nucleus with excessive marginal clumping of chromatin (Fig. 6E, F).

Examination of lung sections of rats in BM-MSCG, revealed marked improvement in lung ultra-structure. Type I \& II pneumocytes showed apparently normal ultrastructure with euchromatic nuclei. Type II pneumocytes revealed most of lamellar bodies with their typical lamellar pattern, together with enhanced exocytosis into alveolar lumen (Fig. 7A). Prominent microvilli were apparent on their apical border. Endothelium of blood capillaries depicted normal appearance with regular nuclear outline and intact junctional folds. Inter-alveolar septum showed minimal deposition of collagen fibers (Fig. 7C, D). Whereas, in CFG extensive degenerative changes were 


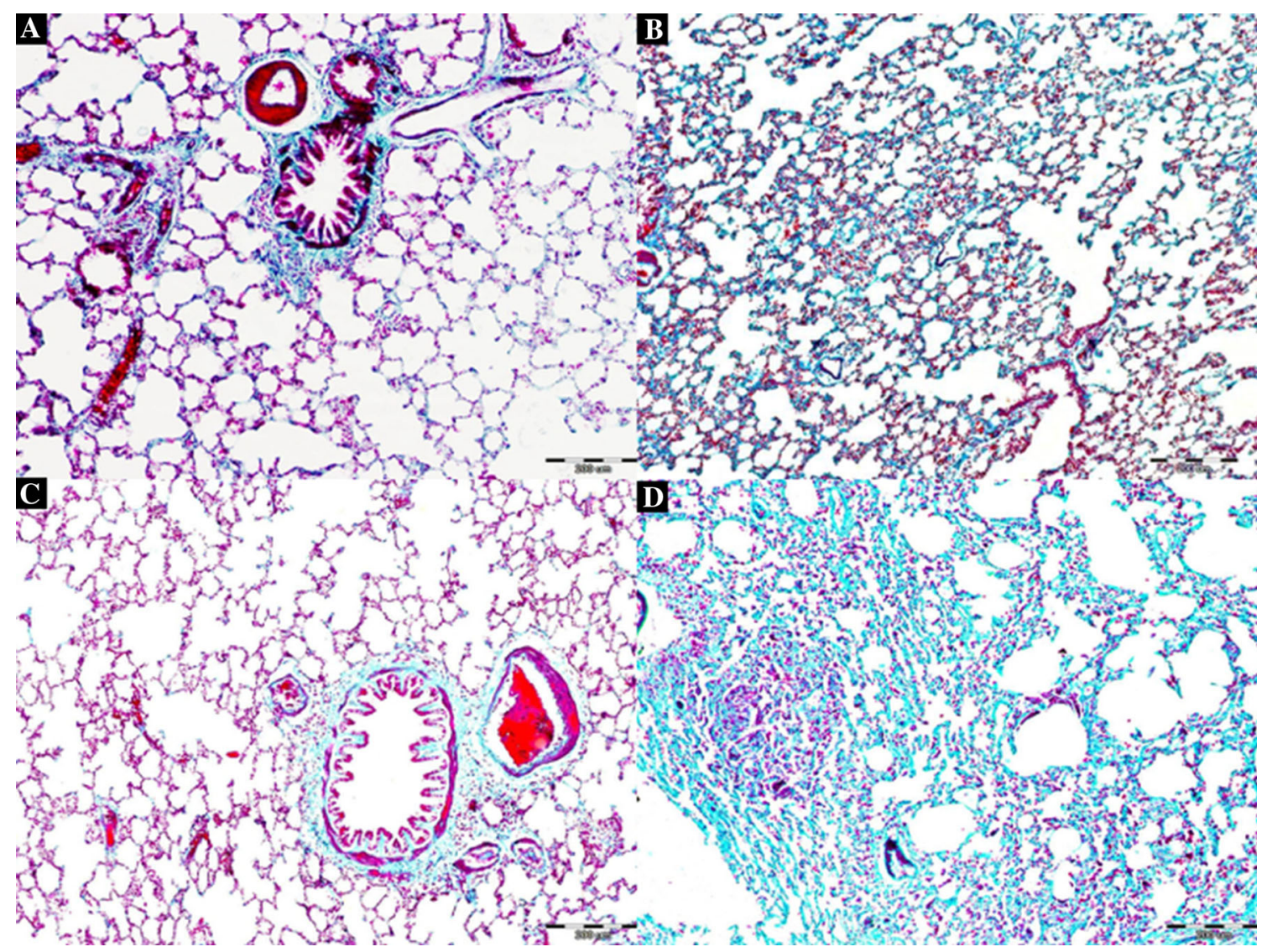

Fig. 5 Masson's Trichrome stained lung sections. A CG; normal distribution of trichrome green stained areas is observed in interalveolar septa, around blood vessels and peribronchiolar. B FG; excessive deposition of collagen in inter-alveolar septa, around blood vessels and peribronchiolar is seen as denoted by increased green

encountered in type I \& type II pneumocytes, with disorganization of lamellar bodies. Detachment and sloughing of degenerated type I pneumocytes into alveolar lumen was noticed in this group, together with alveolar macrophages. Apoptotic bodies and rarified cells were also seen. Moreover, excessive collagen deposition was observed within inter-alveolar septum (Fig. 7E, F).

\section{Discussion}

Most etiologies that affect the lung and lead to lung fibrosis, show a direct effect on the capacity of lung renewal leading to eventual permanent lung fibrosis [39]. The use of stem cells could thus be an important potential promising option in lung tissue regeneration to trigger a paradigm shift from traditional supportive therapy to effective therapy [40-43]. In such a context, it was the scope of the current study to assess the ameliorative effect of MSCs on BLM induced pulmonary fibrosis in rat models. Moreover, combining histological assessment with trichrome stained areas. C BM-MSCsG; showing apparent limited and focal distribution of green colored trichrome stained areas within the inter-alveolar septa. D CFG; apparent increase in green colored trichrome stained areas is noticed within the inter-alveolar septa. (Masson's trichrome, A-D $\times 100$ )

physiological tests for lung functions, presents a novel approach for a more accurate evaluation of lung fibrosis and assessment of the efficacy of the therapeutic strategy.

In this study, pulmonary fibrosis was induced by BLM referring to established data from previous research work [44-47]. There is a range of potential routes of BLM administration in rodents, including intravenous (IV), subcutaneous (SC), intranasal, and intratracheal (IT), the latter has been by far the most preferred mode of administration due to its direct toxic and sustained effect on the lung tissue. Futhermore, it induces a classical picture of lung fibrosis, thus providing a valid model for experimental therapeutic studies [48].

Safety of the used vehicle with BLM (saline) was confirmed histologically, where the examination of lung tissue of CG revealed normal histological features. In consequence, the different histological changes that were encountered in BLM treated group FG could be referred to the impact of BLM toxicity.

Though histological alteration resulting from BLM administration is the gold standard confirmatory method 


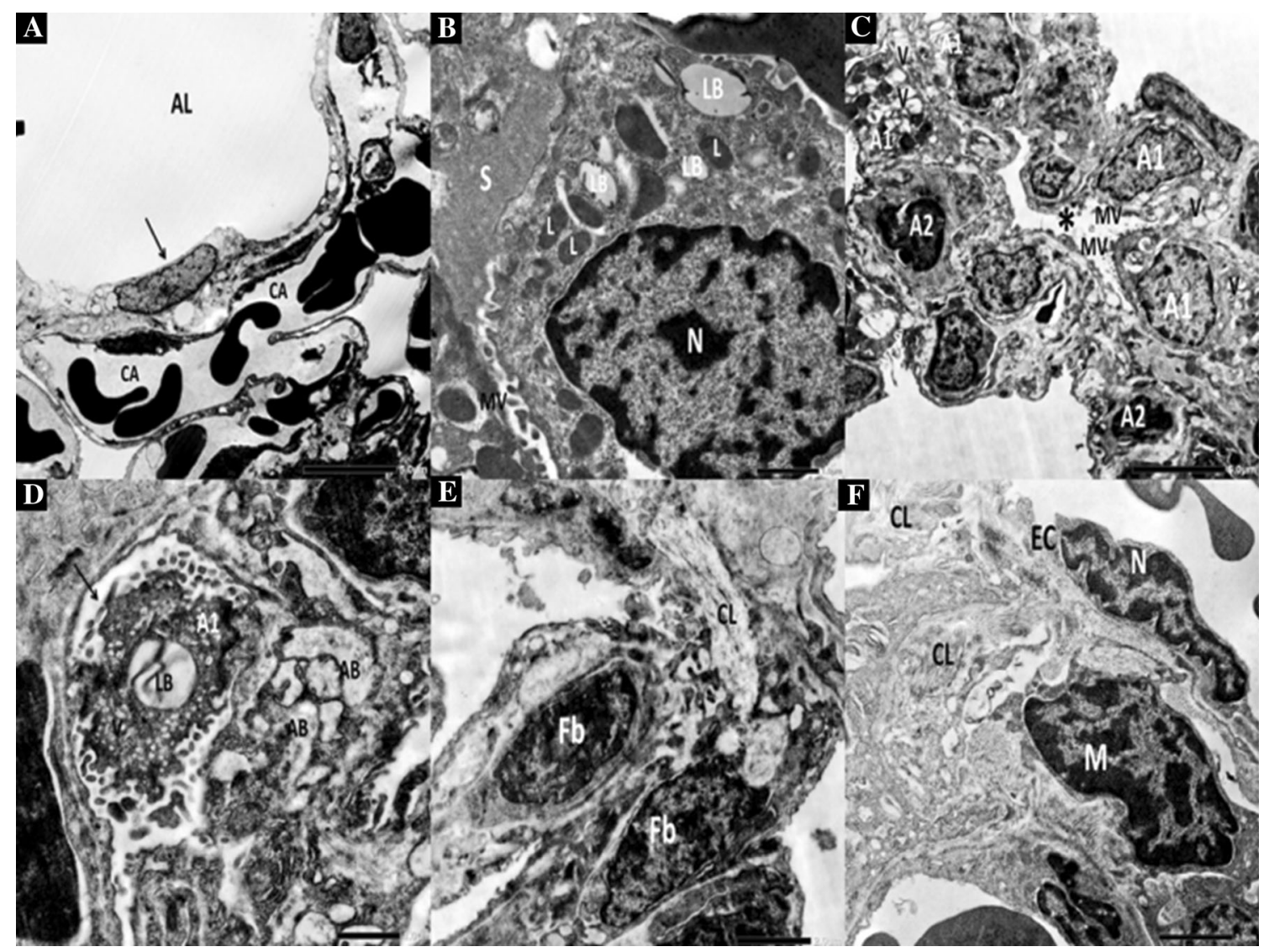

Fig. $6 \mathbf{A}$ and $\mathbf{B}$ Electron photomicrographs of CG. A Type I pneumocyte (arrow) is seen with regular outline and euchromatic nucleus. Patent alveolar space (AL) is observed. CA; blood capillary. B A Type II pneumocyte appears with a prominent microvillous boarder (MV) and euchromatic nucleus (N) facing a patent alveolar space filled by surfactant (S). Type II cell exhibits lamellar bodies (LB) and lysosomes (L) in apical cytoplasm. C-F Electron photomicrographs of FG. (C) Some type II pneumocytes (A1) show vacuolated lamellar bodies (V) together with short irregular microvilli (MV). Other Type II cells (A2) depict dark, irregular nuclei with marginal chromatin clumping. Marked narrowing of the alveolar lumen is noticed (asterisk). (D) Part of a type II pneumocyte (A1), with marked cytoplasmic vacuoles (V) and degenerated lamellar bodies (LB), is seen sloughed in the lumen (arrow). Some apoptotic bodies $(\mathrm{AB})$ are noticed within the lumen. (E) Prominent Fibroblasts $(\mathrm{Fb})$ are observed together with evident collagen (CL) deposition within the inter-alveolar septum. (F) An endothelial cell (EC) depicts irregular nucleus $(\mathrm{N})$ with excessive marginal clumping of chromatin. Notice massive collagen (CL) deposition together with marked thickening of inter-alveolar septum. An inter-alveolar macrophage $(\mathrm{M})$ is also seen. $(\mathrm{A} \times 1500, \mathrm{~B} \times 5000, \mathrm{C} \times 1500, \mathrm{D} \times 5000, \mathrm{E}$ and $\mathrm{F} \times 3000)$ for developing lung fibrosis yet, lung function tests were further assessed and results showed a significant reduction in MRV, FVC, and FEV1 in FG and CFG compared to normal control rats denoting the presence of restrictive lung disease.

BLM cytotoxicity encloses oxidative stress as one of the mechanisms of the induced lung tissue injury [49, 50], where BLM can bind Fe(II) forming a complex, which is subsequently oxidized to $\mathrm{Fe}(\mathrm{III})$ in presence of $\mathrm{O} 2$, resulting in the reduction of oxygen to free radicals and production of reactive oxygen species (ROS), such as, $\mathrm{O} \overline{2}$, hydroxyl radicals, and Fe(III). Then, this bleomycin complex binds to the DNA helix through a nucleophilic bond, resulting in DNA strand breaks. In addition, membrane lipid peroxidation and subsequent membrane damage occur.

Histological examination of $\mathrm{H} \& \mathrm{E}$ stained sections from the BLM induced fibrosis group FG, revealed evident distortion of lung architecture, where marked thickening of the inter-alveolar septa and collapsed alveoli were noticed in a patchy distribution over much of the lung tissue. Induced lung fibrosis was further confirmed by histomorphometric analysis of trichrome stained sections that showed a significant increase in the percentage area of collagen deposition in the induced fibrosis group in comparison to the control group. This can be attributed to the effect of BLM, where it stimulates the alveolar macrophages for the production of inflammatory and profibrotic 


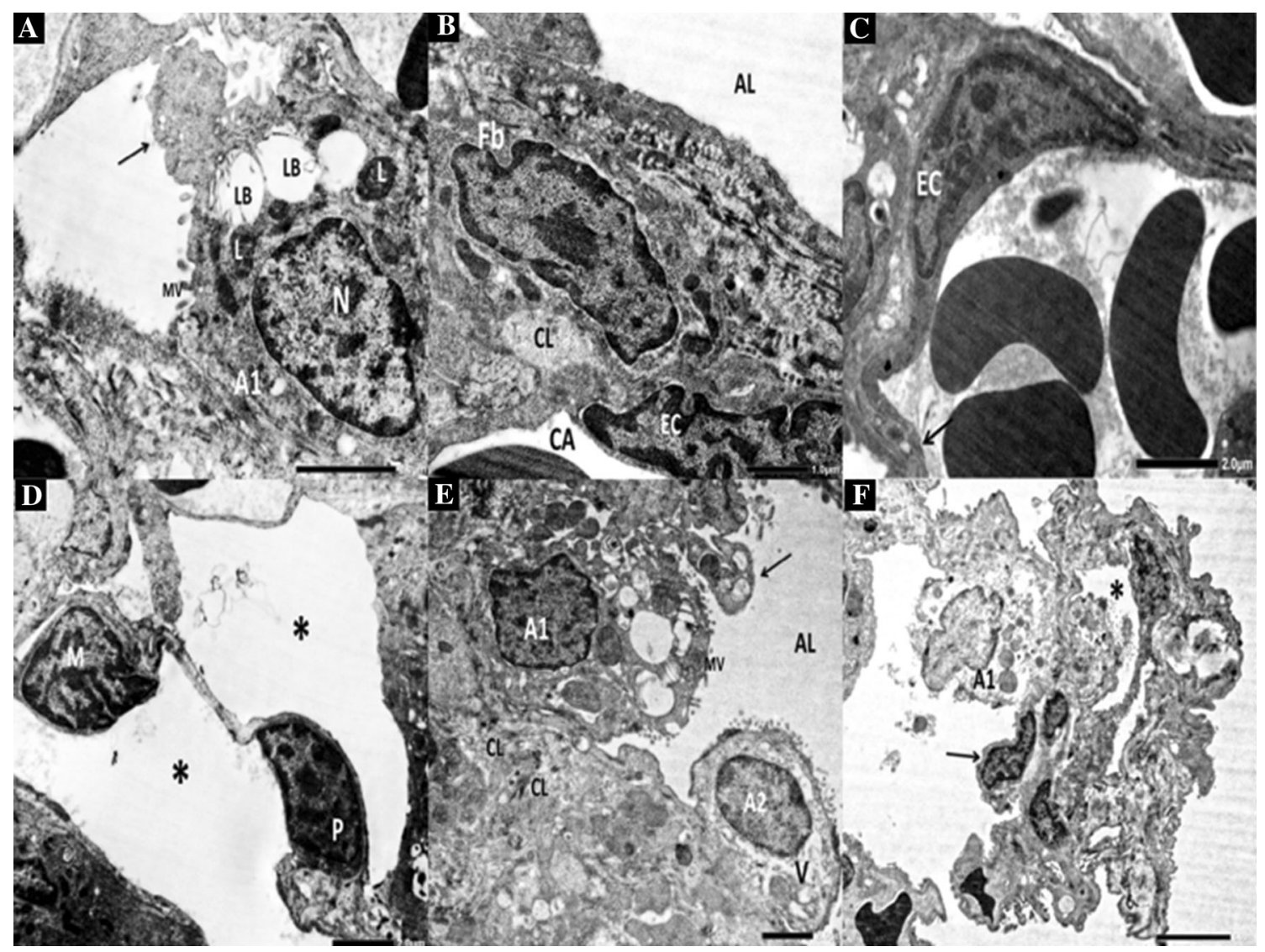

Fig. 7 A-D Electron photomicrographs of BM-MSCsG. A This electron micrograph exhibits a type II pneumocyte cell (A1) in a state of exocytosis of lamellar bodies (LB) into the lumen. The nucleus (N) appears euchromatic. Microvilli (MV) are apparently normal. In addition, lysosomes (L) are noticed in apical part. B A Fibroblast $(\mathrm{Fb})$ together with minimal collagen deposition (CL) are observed within the inter-alveolar septum. An Endothelial cell (EC) is seen with an apparent normal nucleus. (AL); Alveolar lumen, (CA); capillary lumen. C An endothelial cell (EC) is observed with apparently normal nucleus and chromatin distribution, together with intact junctional fold (arrow). D This figure shows patent alveolar lumina (asterisks) lined by type I pneumocyte $(\mathrm{P})$ with apparent normal euchromatic

cytokines such as interleukin-1(IL-1), macrophage inflammatory protein-1, and others. Nevertheless, BLM induces type II pneumocyte hyperplasia that unlike normal type II cells, contributes to the secretion of some of these cytokines. Such cytokines lead to further proliferation and activation of fibroblasts with subsequently increased collagen deposition and eventually alveolar collapse [51, 52]. Moreover, some of these cytokines act as chemoattractants thus leading to inflammatory cell recruitment and cellular infiltration [53, 54].

This came in agreement with the present study, where massive cellular infiltration was also noticed within the inter-alveolar septa and peribronchiolar. Moreover, the electron microscopic results came in accordance with the light microscopic results, where marked collagen fibers nucleus. Inter-alveolar macrophage $(\mathrm{M})$ is also seen. $(\mathrm{E} \& \mathrm{~F})$ Electron photomicrographs of CFG. E A type II pneumocyte (A1) exhibits some vacuolated lamellar bodies and short irregular microvilli (MV). Another Type II cell (A2) shows excessive cytoplasmic vacuolation (V). Several apoptotic bodies are observed (arrow). Notice marked collagen (CL) deposition within inter-alveolar septum. (AL); Alveolar lumen. F A type II pneumocyte (A1) shows excessive cytoplasmic vacuolation. A type I pneumocyte (arrow) appears rarified and detached from its basement membrane. Apparent Narrowing of alveolar lumen is noticed (asterisk). $(\mathrm{A} \times 4000, \mathrm{~B} \times 5000$, $\mathrm{C} \times 3000 \mathrm{D} \times 2500, \mathrm{E} \times 2000, \mathrm{~F} \times 1200)$

deposition was observed within the inter-alveolar septa, together with evident fibroblasts,

Electron microscopic results of the BLM induced fibrosis group, revealed variable degenerative changes, where type I pneumocytes were infrequently encountered, unlike type II pneumocytes that were more frequently seen. This can be attributed to the direct toxic effect of BLM on type I pneumocyte $[55,56]$. In addition, variable degenerative changes depicted by type II pneumocytes can be referred to membrane lipid peroxidation effect induced by the generated free oxygen radicals.

Furthermore, endothelial cells of inter-alveolar blood capillaries revealed an irregular outline of the nucleus with excessive marginal clumping of chromatin. In accordance, Allawzi A ET stated that BLM increases the vascular 
permeability of pulmonary capillaries with subsequent initial congestion of the lung. This can explain vascular congestion that was observed histologically in lung sections of fibrosis group. Then, this increased permeability contributes to the inflammatory state that eventually ends with fibrosis [50, 57].

There is certainly loads of good evidence to suggest that lung fibrosis is a vicious circle where the initial injury promotes fibrosis through impaired signal regulation. This can occur from alveolar epithelial cell dysfunction with enhanced integrin production and activation, intensified mesenchymal-epithelial interactions by disrupted cell membrane activity or epithelial mesenchymal transition (EMT). Another hypothesis is that fibrogenesis is driven by dysregulated fibroblast/myo-fibroblast responses to epithelial injury $[58,59]$.

The origin of myofibroblasts in lung fibrosis has been questioned for many years and epithelial mesenchymal transition (EMT) as a source of these cells has been suggested. Nevertheless, lineage tracing in transgenic mice indicates that the contribution of epithelial cells that have undergone EMT could be insignificant for the fibroblast population. Rather, recent findings indicate that EMT facilitates a pro-fibrotic microenvironment by inducing local fibroblasts to be triggered by the paracrine effect of some factors produced by alveolar epithelial cells [60, 61].

Nevertheless, increased collagen production seems to be more likely to be related to BLM reaction involving increased permeability of protein influx and inflammatory cells. As such, fibroblasts may be exposed to quantities of mediators found in the bloodstream, produced by resident cells of lung or those that enter lung tissues [62].

After binding to of BLM complex to DNA and Fe(II) oxidation into $\mathrm{Fe}(\mathrm{III})$, a nucleophilic bond occurs at the DNA desoxyribose C4' position. This will lead eventually to a break in the DNA strand. Furthermore, the free radicals produced by this process, leading to enhanced DNA breaks that ultimately lead to cell death. This can explain the nuclear changes encountered ultra-structurally, such as shrunken irregular nuclei with increased clumped chromatin [15, 63].

Moreover, $\mathrm{Fe}(\mathrm{II})$ regeneration provides the ternary complex BLM-Fe(II)-O2 with catalytic activity, where it is assumed that every BLM molecule can produce from 8 to 10 DNA breaks $[15,46,63,64]$. Thus, enhancing more the cellular degenerative changes. Apoptotic bodies that were encountered ultra- structurally, can be correlated to BLM direct toxic effect on the DNA, where it may cause single(SSB) or double-stranded (DSB) DNA breaks and can induce cell death by pseudo-apoptosis-similar to apoptosis but characterized by rapid DNA fragmentation-or mitotic cell death $[65,66]$. These degenerative changes had an impact on lung functions as was confirmed by the results of lung function tests where minute Respiratory Volume (MRV), forced expiratory volume (FEV1), and forced vital capacity (FVC) showed marked reduction in FG and CFG. Restrictive lung diseases including fibrosis reduce the FVC and FEV1 proportionally thus the FEV1/FVC ratio is either maintained normal or may be increased if the FVC is decreased more as compared to FEV1. FEV1/FVC ratio in this study was indifferent between groups, though FEV1 and FVC were significantly decreased in FG and CFG in comparison to CG and BM-MSCsG denoting the existence of a restrictive lung abnormality in the two former groups.

In the current study, the homing of the male donor cells was confirmed in the injured lung of female recipients by PCR for the SRY gene which is found on the Y chromosome, and by the presence of labeled MSCs in the lung tissue visualized by confocal microscope shortly after MSCs injection.

Homed BM-MSCs attenuated lung fibrosis significantly, as was evident on histological examination of lung sections from the MSC's treated group, where marked decreased deposition of collagen within the inter-alveolar septa was observed. Most of the alveoli appeared patent with thin inter-alveolar septa. Histomorphometric results of trichrome stained sections further confirmed such an ameliorative effect of stem cell therapy, where there was a significant decrease in the percentage area of collagen deposition and an increase in the alveolar surface area as compared to the BLM induced fibrosis group and the group that received cell free media.

It is worth mentioning that collagen deposition was significantly decreased in the MSC's treated group in comparison to the control group. Such a finding can be referred to the significant therapeutic potential of BMMSC's thus overcoming even mild injurious effects of pollutants in the air, which might affect lung tissue of control group rats.

This came in accordance with the ultra-structural results that showed evident restoration of ultra-structural features of pneumocytes types I and \& II. Endothelium of blood capillaries had a normal appearance with a regular nuclear outline and intact junctional folds. The inter-alveolar septum showed minimal deposition of collagen fibers.

Together with previous studies, it can be concluded based on the findings of the present study that the administration of and MSCs can mitigate lung fibrosis. Those results agreed with lung function results that showed great improvement in MRV, FEV1, and FVC where they all increased reaching normal values with no significant difference with $\mathrm{CG}$, denoting the restoration of the lung ventilatory functions [67].

The present evidence relies on soluble mediators released by MSCs such as IL-1 receptor antagonist, IL-10, keratinocyte growth factor, hepatocyte growth factor, 
angiopoietin 1 , and transforming growth factor- $\beta$ appear to play a significant role in the repair of acute and fibrotic injuries $[68,69]$. These cytokines are characterized by being anti-inflammatory and anti-fibrotic. It has been established that IL-10 suppresses the functions of macrophages and neutrophils [70]. Among key functions of (TGF)- $\beta 1$ are regulation of inflammatory and proliferation processes in addition to controlling cell growth, cell proliferation, cell differentiation, and apoptosis [71].

Furthermore, MSCs can promote the polarization of macrophages from a pro-inflammatory phenotype to an anti-inflammatory phenotype through the production of immunosuppressive molecules and metabolites, Also, MSCs could directly dissolve fibrosis through the secretion of matrix metalloproteinase, an enzyme that is capable of degrading the extracellular matrix [72]. Adding to this regenerative power of MSCs that depends on its paracrine effect, these cells could still differentiate to the injured cell phenotype and thus restore the structure and function of injured tissue.

The histological examination of lung tissue in CFC further confirmed that the restoration of lung structure and function in BM-MSC treated group was due to the regenerative power of MSCs, as CFG showed massive collapsing of alveoli together with increased septal thickness and evident cellular infiltration. Such results prove that free cell media did not have any therapeutic effect; nevertheless, instead, there was a prolonged exposure to BLM injurious effect on lung tissue without an opposing therapeutic option, where histological features of fibrosis and degeneration were even more pronounced than that seen in the fibrotic untreated group.

In such a context, MSCs proved to be a therapeutic strategy with remarkable ameliorative potential in the induced lung fibrosis model in the current study.

In conclusion, the BLM experimental model proved to be a reproducible model to mimic lung fibrosis. The methods implemented in the present work confirmed that the intravenous injection is an ultimate approach ensuring engraftment of transplanted MSCs. The applied techniques for morphological and functional assessment proved the efficiency of transplanted BM-MSCs in restoring the lung architecture and functions in the BLM experimentally induced fibrosis. The established results on the experimental level should enhance clinical trials that would lead to the application of MSCs as a therapeutic strategy for treatment and preventing the progression of lung fibrosis.

Acknowledgements Authors would like to acknowledge the Center of Excellence for Research in Regenerative Medicine and its Applications, CERRMA (STDF funded), for providing the adequate facilities and environment for the processing and characterization of the BM-MSCs under completely sterile conditions.
Author contribution DMZ Carried out the experimental part, take a part in planning the experiment, writing the manuscript and data analysis. NMZ Supervised the practical work, helped in explaining the results, and contributed in revising the manuscript writing and organization SAAA Supervised the practical work, helped in explaining the results, and contributed in revising the manuscript writing and organization RAM Carried out the Stem cells isolation, culture, characterization and labeling, contributed in study design,writing, supervision and analysis of data. RAAM Carried out the histological assessment, contributed in study design, planning the experiment writing, supervision and analysis of data.

\section{Compliance with ethical standards}

Conflict of interest The authors declare that they have no conflicts of interest.

Ethical statement All experiments were approved by the Medical Ethics Committee of Alexandria Faculty of Medicine (IRB NO: 00012098-FWA NO: 00018699).

\section{References}

1. Zaghloul MS, Abdel-Salam RA, Said E, Suddek GM, Salem HAR. Attenuation of Bleomycin-induced pulmonary fibrosis in rats by flavocoxid treatment. Egypt $\mathbf{J}$ Basic Appl Sci. 2017;4:256-63.

2. Wolters PJ, Blackwell TS, Eickelberg O, Loyd JE, Kaminski N, Jenkins $G$, et al. Time for a change: is idiopathic pulmonary fibrosis still idiopathic and only fibrotic? Lancet Respir Med. 2018;6:154-60.

3. King CS, Nathan SD. Idiopathic pulmonary fibrosis: effects and optimal management of comorbidities. Lancet Respir Med. 2017;5:72-84.

4. Johannson KA, Vittinghoff E, Morisset J, Wolters PJ, Noth EM, Balmes JR, et al. Air pollution exposure is associated with lower lung function, but not changes in lung function, in patients with idiopathic pulmonary fibrosis. Chest. 2018;154:119-25.

5. Bellou V, Belbasis L, Konstantinidis A, Evangelou E. Tobacco smoking and risk for idiopathic pulmonary fibrosis: a prospective cohort study in UK Biobank. Eur Respir J. 2017;50:PA4887.

6. Spagnolo P, Balestro E, Aliberti S, Cocconcelli E, Biondini D, Casa GD, et al. Pulmonary fibrosis secondary to COVID-19: a call to arms? Lancet Respir Med. 2020;8:750-2.

7. Carvajalino S, Reigada C, Johnson MJ, Dzingina M, Bajwah S. Symptom prevalence of patients with fibrotic interstitial lung disease: a systematic literature review. BMC Pulm Med. 2018;18:78.

8. Orens JB, Garrity ER Jr. General overview of lung transplantation and review of organ allocation. Proc Am Thorac Soc. 2009;6:13-9.

9. Biehl JK, Russell B. Introduction to stem cell therapy. J Cardiovasc Nurs. 2009;24:98-103.

10. Sottocornola R, Celso CL. Dormancy in the stem cell niche. Stem Cell Res Ther. 2012;3:10.

11. Ying QL, Wray J, Nichols J, Batlle-Morera L, Doble B, Woodgett J, et al. The ground state of embryonic stem cell self-renewal. Nature. 2008;453:519-23.

12. Taparra K, Liu H, Polley MY, Ristow K, Habermann TM, Ansell SM. Bleomycin use in the treatment of Hodgkin lymphoma (HL): toxicity and outcomes in the modern era. Leukemia Lymphoma. 2019:1-11. 
13. Chandra S. Ovarian immature teratoma associated with pregnancy. Online J Health Allied Sci. 2019;18:14.

14. Fiorentzis M, Kalirai H, Katopodis P, Seitz B, Viestenz A, Coupland SE. Electrochemotherapy with bleomycin and cisplatin enhances cytotoxicity in primary and metastatic uveal melanoma cell lines in vitro. Neoplasma. 2018;65:210-5.

15. Walters DM, Kleeberger SR. Mouse models of bleomycin-induced pulmonary fibrosis. Curr Protoc Pharmacol. 2008; Chapter 5:Unit 5.46.

16. Saijo Y. DLI induced by nonmolecular target antineoplastic drugs: what are the characteristics of DLI in nonmolecular target antineoplastic drugs? In: Drug-Induced Lung Injury. Singapore: Springer; 2018. p. 129-38.

17. Oka Y, Mitsui M, Kitahashi T, Sakamoto A, Kusuoka O, Tsunoda $\mathrm{T}$, et al. A reliable method for intratracheal instillation of materials to the entire lung in rats. $\mathrm{J}$ Toxicol Pathol. 2006;19:107-9.

18. Davies OG, Cooper PR, Shelton RM, Smith AJ, Scheven BA. Isolation of adipose and bone marrow mesenchymal stem cells using CD29 and CD90 modifies their capacity for osteogenic and adipogenic differentiation. $J$ Tissue Eng. 2015;6:2041731415592356.

19. Lotfy A, Salama M, Zahran F, Jones E, Badawy A, Sobh M. Characterization of mesenchymal stem cells derived from rat bone marrow and adipose tissue: a comparative study. Int J Stem Cells. 2014;7:135-42.

20. Zhang L, Chan C. Isolation and enrichment of rat mesenchymal stem cells (MSCs) and separation of single-colony derived MSCs. J Vis Exp. 2010;37:e1852.

21. Huang S, Xu L, Sun Y, Wu T, Wang K, Li G. An improved protocol for isolation and culture of mesenchymal stem cells from mouse bone marrow. J Orthop Translat. 2015;3:26-33.

22. Li W, Zeng J, Zhu G, Dong Y, Xie D, Lai R. In vitro cultivation technology of rat bone marrow mesenchymal stem cells. J Biomater Tissue Eng. 2019;9:62-8.

23. Karlsen TA, Brinchmann JE. Expression of inflammatory cytokines in mesenchymal stromal cells is sensitive to culture conditions and simple cell manipulations. Exp Cell Res. 2019;374:122-7.

24. Penfornis P, Pochampally R. Colony forming unit assays. In: Mesenchymal stem cells. Berlin: Springer; 2016. p. 159-69.

25. Khan MR, Chandrashekran A, Smith RK, Dudhia J. Immunophenotypic characterization of ovine mesenchymal stem cells. Cytometry A. 2016;89:443-50.

26. Green MR, Sambrook J. Estimation of cell number by hemocytometry counting. Cold Spring Harb Protoc. 2019. https://doi.org/ 10.1101/pdb.prot097980.

27. Srour N, Thébaud B. Mesenchymal stromal cells in animal bleomycin pulmonary fibrosis models: a systematic review. Stem cells Transl Med. 2015;4:1500-10.

28. Ghabrial MM, Salem MF, El Ela AM, El Deeb SA. The possible therapeutic role of mesenchymal stem cells in amiodarone-induced lung injury in adult male albino rats. Tanta Med J. 2018:46:172.

29. Jalalie L, Rezaie MJ, Jalili A, Rezaee MA, Vahabzadeh Z, Rahmani MR, et al. Distribution of the CM-Dil-labeled human umbilical cord vein mesenchymal stem cells migrated to the cyclophosphamide-injured ovaries in C57BL/6 mice. Iran Biomed J. 2019;23:200-8.

30. Wang LJ, Chen YM, George D, Smets F, Sokal EM, Bremer EG, et al. Engraftment assessment in human and mouse liver tissue after sex-mismatched liver cell transplantation by real-time quantitative PCR for Y chromosome sequences. Liver Transpl. 2002;8:822-8.

31. Liu T, Zhu K, Ke C, Yang S, Yang F, Li Z, et al. Mesenchymal stem cells inhibited development of lung cancer induced by chemical carcinogens in a rat model. Am J Transl Res. 2017;9:2891-900.

32. Ahmed SK, Mohammed SA, Khalaf G, Fikry H. Role of bone marrow mesenchymal stem cells in the treatment of CCL4 induced liver fibrosis in albino rats: a histological and immunohistochemical study. Int J Stem Cells. 2014;7:87-97.

33. El-Magd MA, Mohamed Y, El-Shetry ES, Elsayed SA, Abo Gazia M, Abdel-Aleem GA, et al. Melatonin maximizes the therapeutic potential of non-preconditioned MSCs in a DEN-induced rat model of HCC. Biomed Pharmacother. 2019;114:108732.

34. Drury R, Wallington E. Light microscope and slide preparation. Carleton's histological technique. London: Oxford University Press; 1980.

35. Bozzola JJ. Specimen staining and contrast methods for transmission electron microscopy. In: Electron Microsocopy Principles and Techniques for Biologists. Jones and Bartlett Publishers, Inc.; 1992. p. 16-51.

36. Glauert A. Fixation, dehydration and embedding of biological specimens. Practical methods in electron microscopy. Part I. Amsterdam: North-Holland Publishing Company; 1975.

37. Graham R, Gray T, Bancroft J, Stevens A. Electron microscopy 2: practical procedures. Theory and Practice of Histological Techniques 4th ed New York: Churchill-Livingstone. 1996.

38. Read CB, Vidakovic B. Encyclopedia of statistical sciences. New Jersey: Wiley; 2006.

39. Brandsma CA, de Vries M, Costa R, Woldhuis RR, Königshoff $\mathrm{M}$, Timens W. Lung ageing and COPD: is there a role for ageing in abnormal tissue repair? Eur Respir Rev. 2017;26:170073.

40. Shen Q, Chen B, Xiao Z, Zhao L, Xu X, Wan X, et al. Paracrine factors from mesenchymal stem cells attenuate epithelial injury and lung fibrosis. Mol Med Rep. 2015;11:2831-7.

41. Sellares J, Huleihel L, Cardenes N, Alvarez D, Sakamoto K, Yu $\mathrm{G}$, et al. Modified mesenchymal stem cells using mirna transfection could modify lung fibrosis progression. In: B28 advances in stem cells in injury and repair for 2016: American Thoracic Society; 2016. p. A3081.

42. Huleihel L, Sellares J, Cardenes N, Álvarez D, Faner R, Sakamoto $\mathrm{K}$, et al. Translational research in acute lung injury and pulmonary fibrosis: modified mesenchymal stem cells using miRNA transduction alter lung injury in a bleomycin model. Am J Physiol Lung Cell Mol Physiol. 2017;313:L92-103.

43. Mansouri N, Willis G, Fernandez-Gonzalez A, Reis M, Mitsialis A, Kourembanas S. Mesenchymal stem cell exosomes ameliorate experimental idiopathic pulmonary fibrosis by modulating alveolar macrophage phenotype and monocyte recruitment. In: D97 If you love it, let it go: Exosomes and secretomes. American Thoracic Society; 2018. p. A7402.

44. McElroy MC, Anderson M, Young A, Nath P, Madden S, Milne $A$, et al. Respiratory function and quantitative measurement of fibrosis in a rat model of bleomycin-induced lung fibrosis. In: C75 Fibrosis: current and future approaches: American Thoracic Society; 2017. p. A6365.

45. Zhao Y, Liu T, Gonzalez De Los Santos F, Wu Z, Phan S. ILC2 promotes bleomycin-induced pulmonary fibrosis though IL-33/ ST2 signaling pathway. In: B107 Mechanistic advances in pulmonary fibrosis: American Thoracic Society; 2018. p. A4345.

46. Liu T, De Los Santos FG, Phan SH. The bleomycin model of pulmonary fibrosis. In: Fibrosis. Singapore: Springer; 2017. p. $27-42$.

47. Mouratis MA, Aidinis V. Modeling pulmonary fibrosis with bleomycin. Curr Opinion Pulm Med. 2011;17:355-61.

48. Egger C, Cannet C, Gérard C, Jarman E, Jarai G, Feige A, et al. Administration of bleomycin via the oropharyngeal aspiration route leads to sustained lung fibrosis in mice and rats as quantified by UTE-MRI and histology. PLoS One. 2013;8:e63432. 
49. Iyer SS, Ramirez AM, Ritzenthaler JD, Torres-Gonzalez E, Roser-Page S, Mora AL, et al. Oxidation of extracellular cysteine/cystine redox state in bleomycin-induced lung fibrosis. Am Physiol Lung Cell Mol Physiol. 2009;296:L37-45.

50. Allawzi A, Elajaili H, Redente EF, Nozik-Grayck E. Oxidative toxicology of bleomycin: role of the extracellular redox environment. Curr Opin Toxicol. 2019;13:68-73.

51. Reinert T, Baldotto CS, Nunes FA, Scheliga AA. Bleomycininduced lung injury. J Cancer Res. 2013;2013:9.

52. Kim MS, Baek AR, Lee JH, Jang AS, Kim DJ, Chin SS, et al. IL37 attenuates lung fibrosis by inducing autophagy and regulating TGF- $\beta 1$ production in mice. J Immunol. 2019;203:2265-75.

53. Dong SH, Liu YW, Wei F, Tan HZ, Han ZD. Asiatic acid ameliorates pulmonary fibrosis induced by bleomycin (BLM) via suppressing pro-fibrotic and inflammatory signaling pathways. Biomed Pharmacother. 2017;89:1297-309.

54. Zhang L, Wang Y, Wu G, Xiong W, Gu W, Wang CY. Macrophages: friend or foe in idiopathic pulmonary fibrosis? Respir Res. 2018;19:170.

55. Kobzik L, Sholl L. Pulmonary pathology of ards: diffuse alveolar damage. In: Choi A. Acute respiratory distress syndrome. Boca Raton: CRC Press; 2016. p. 46-58.

56. Hughes KT, Beasley MB. Pulmonary manifestations of acute lung injury: more than just diffuse alveolar damage. Arch Pathol Lab Med. 2017;141:916-22.

57. Phinney DG. Building a consensus regarding the nature and origin of mesenchymal stem cells. J Cell Biochem Suppl. 2002;38:7-12.

58. Xia T, Zhang L, Chen F, Song K. Cells and cellular interactions in the pathogenesis of idiopathic pulmonary fibrosis. Postgrad Med J. 2016;29:314-8.

59. Decaris ML, Gatmaitan M, FlorCruz S, Luo F, Li K, Holmes WE, et al. Proteomic analysis of altered extracellular matrix turnover in bleomycin-induced pulmonary fibrosis. Mol Cellular Proteomics. 2014;13:1741-52.

60. Hill C, Jones MG, Davies DE, Wang Y. Epithelial-mesenchymal transition contributes to pulmonary fibrosis via aberrant epithelial/fibroblastic cross-talk. J Lung Health Dis. 2019;3:31-5.

61. Nieto MA, Huang RY, Jackson RA, Thiery JP. EMT:2016. Cell. 2016;166:21-45.
62. Hay J, Shahzeidi S, Laurent G. Mechanisms of bleomycin-induced lung damage. Arch Toxicol. 1991;65:81-94.

63. Galm U, Hager MH, Van Lanen SG, Ju J, Thorson JS, Shen B. Antitumor antibiotics: bleomycin, enediynes, and mitomycin. Chem Rev. 2005;105:739-58.

64. Hecht SM. Bleomycin: new perspectives on the mechanism of action. J Nat Prod. 2000;63:158-68.

65. Tounekti O, Pron G, Belehradek J Jr, Mir LM. Bleomycin, an apoptosis-mimetic drug that induces two types of cell death depending on the number of molecules internalized. Cancer Res. 1993;53:5462-9.

66. Tounekti O, Kenani A, Foray N, Orlowski S, Mir LM. The ratio of single-to double-strand DNA breaks and their absolute values determine cell death pathway. Br J Cancer. 2001;84:1272-9.

67. Ranu H, Wilde M, Madden B. Pulmonary function tests. Ulster Med J. 2011;80:84.

68. Akram KM, Samad S, Spiteri M, Forsyth NR. Mesenchymal stem cell therapy and lung diseases. In: Mesenchymal stem cells-basics and clinical application II: Berlin: Springer; 2012. p. 105-29.

69. Ardhanareeswaran K, Mirotsou M. Lung stem and progenitor cells. Respiration. 2013;85:89-95.

70. Kyurkchiev D, Bochev I, Ivanova-Todorova E, Mourdjeva M, Oreshkova T, Belemezova K, et al. Secretion of immunoregulatory cytokines by mesenchymal stem cells. World J Stem Cells. 2014;6:552-70.

71. Sanjabi S, Zenewicz LA, Kamanaka M, Flavell RA. Anti-inflammatory and pro-inflammatory roles of TGF- $\beta$, IL-10, and IL22 in immunity and autoimmunity. Curr Opin Pharmacol. 2009;9:447-53.

72. Hardjo M, Miyazaki M, Sakaguchi M, Masaka T, Ibrahim S, Kataoka K, et al. Suppression of carbon tetrachloride-induced liver fibrosis by transplantation of a clonal mesenchymal stem cell line derived from rat bone marrow. Cell Transplant. 2009;18:89-99.

Publisher's Note Springer Nature remains neutral with regard to jurisdictional claims in published maps and institutional affiliations. 